\title{
The link between chronic obstructive pulmonary disease phenotypes and histological subtypes of lung cancer: a case-control study
}

This article was published in the following Dove Press journal: International Journal of COPD

\author{
Wei Wang* \\ Mengshuang Xie* \\ Shuang Dou \\ Liwei Cui \\ Chunyan Zheng \\ Wei Xiao \\ Department of Pulmonary Medicine, \\ Qilu Hospital, Shandong University, \\ Jinan, Shandong, China \\ *These authors contributed equally \\ to this work
}

Correspondence: Wei Xiao Department of Pulmonary Medicine, Qilu Hospital, Shandong University, 107 Wenhua West Road, Jinan, Shandong 2500I2, China

Tel +8653182166294

Email xiaowei4226@I63.com
Background: COPD is considered an independent risk factor for lung cancer. COPD and lung cancer are both very heterogeneous diseases, and the study herein investigates the link between COPD phenotypes and specific histological subtypes of lung cancer.

Methods: This case-control study comprised 2,283 patients with newly diagnosed pathological lung cancer and 2,323 non-lung cancer controls. All participants underwent pulmonary function tests. The diagnosis of COPD was based on Global Initiative for Chronic Obstructive Lung Disease criteria. Subtypes of the two diseases were categorized according to 2015 World Health Organization classification of lung cancer and computer quantification of airway collapse on maximum expiratory flow volume. ORs were estimated using logistic regression analysis.

Results: The prevalence of COPD was higher (32.8\%) in lung cancer patients compared to controls (16.0\%). After adjustment for age, sex, body-mass index, and smoking status, the presence of COPD significantly increased the risk of lung cancer (OR 2.88, 95\% CI 2.48-3.34) and all common histological subtypes (ORs 2.04-5.26). Both emphysema-predominant and non-emphysema-predominant phenotypes of COPD significantly increased the risk of lung cancer (OR 4.43, 95\% CI 2.85-6.88; OR 2.82, 95\% CI 2.40-3.31). Higher risk of squamouscell carcinoma and small-cell lung cancer was observed in patients with the emphysemapredominant than the non-emphysema-predominant phenotype (OR 1.73, 95\% CI 1.03-2.89; OR 3.74, 95\% CI 1.64-8.53).

Conclusion: COPD was an independent risk factor for lung cancer and all common histological subtypes. Both emphysema-predominant and non-emphysema-predominant phenotypes of COPD significantly increased the risk of lung cancer. Relative to non-emphysema-predominant phenotype of COPD, emphysema-predominant phenotype had a higher risk of squamous-cell carcinoma and small-cell lung cancer.

Keywords: lung cancer, COPD, risk, phenotype, histology

\section{Introduction}

Lung cancer and COPD are common pulmonary diseases. Lung cancer is the most common cancer and the leading cause of cancer death worldwide. In 2012, an estimated 1.8 million new cases and 1.5 million lung cancer deaths occurred globally, ${ }^{1,2}$ among which a third occurred in China. ${ }^{3,4}$ COPD is another devastating disease that causes progressive and ultimately fatal deterioration of lung function over time. In 2010, the number of COPD cases increased to 384 million worldwide. ${ }^{5}$ In China, it became a topic of increasing concern. ${ }^{6}$ COPD and lung cancer have become the third- and fifth-most common cause of deaths globally, respectively. ${ }^{7}$ The economic and social burdens associated with these diseases have indicated dramatic increases. ${ }^{8,9}$ 
Lung cancer and COPD are interrelated pulmonary diseases. ${ }^{10}$ They share many common risk factors, such as cigarette smoking and other inhalation hazards from occupational, domestic, or outdoor air pollution. ${ }^{11-15}$ The association between COPD and lung cancer risks has been studied extensively over the last 30 years. It has been demonstrated that reduction in forced expiratory volume in 1 second $\left(\mathrm{FEV}_{1}\right)$ is associated with an increase in the risk of lung cancer. ${ }^{16,17}$ Lung cancer incidence among COPD patients with smoking history also appears very high (16.7 per 1,000 person-years). ${ }^{18}$ Moreover, epidemiological studies have found that COPD could increase the risk of lung cancer by two- to sixfold, regardless of smoking habits. ${ }^{19-21}$ Several studies have attempted to summarize possible mechanistic links between COPD and lung cancer. There are numerous arguments supporting a common physiopathology between the two diseases, such as inflammation, extracellular matrix proteolysis, oxidative stress, telomere shortening, and genetic predisposition. ${ }^{22-27}$ However, the exact mechanism connecting the two pathologies remains unclear and needs to be investigated further.

Lung cancer and COPD are heterogeneous diseases with different pathological changes. Lung cancer is characterized by abnormal cell behavior, such as increased proliferation, invasion, and angiogenesis. The World Health Organization (WHO) has classified lung cancer into several subtypes. ${ }^{28}$ On the other hand, COPD is characterized by persistent respiratory symptoms and airflow limitation. The major pathological changes in COPD include emphysema and airway remodeling. ${ }^{29,30}$ Researchers have pointed out that the heterogeneous nature of the two diseases has largely hampered progress toward uncovering this mechanistic link. ${ }^{24,31}$ There is an urgent requirement to clarify the link between COPD phenotypes and histological subtypes of lung cancer.

Generally, subtypes of lung cancer are categorized merely according to histopathology, while phenotypes of COPD can be classified in many ways, such as clinical, pathophysiologic, and radiographic methods. ${ }^{32,33}$ Traditionally, according to dominant pathological changes, patients with COPD can be divided into two most common phenotypes: emphysema-predominant and airway-predominant. ${ }^{34}$ Quantitative computed tomography (QCT) is a common diagnostic method used to derive COPD pathological phenotypes. ${ }^{30}$ However, QCT is not routinely available for patients with chronic airway disease. Furthermore, the high cost and complicated nature of the procedure limits its usage in retrospective clinical studies. Computer quantification of airway collapse (AC) on maximum expiratory flow volume (MEFV) curve is an alternative and reproducible method to predict the presence of emphysema that facilitates the identification of the emphysema-predominant phenotype of COPD..$^{35-37}$

We attempted to gain insight into more specific links between lung cancer and COPD to gain an understanding of the mechanistic link between the two diseases. In this study, we validated the relationship between COPD and lung cancer risk in larger samples, and further explored the link between COPD phenotypes and the risk of specific histological subtypes of lung cancer.

\section{Methods Subjects}

A case-control study was performed using the clinical database of Qilu Hospital, Shandong University, Jinan from 2004 to 2015. Patients with newly pathology-diagnosed lung cancer were enrolled. Non-lung cancer controls were collected from patients undergoing lung-function screening in the corresponding period. All participants underwent pulmonary function tests (PFTs) and chest CT scans. Patients were excluded if they had a history of asthma, bronchiectasis, tuberculosis, pulmonary fibrosis, or other confounding diseases. Data on age, sex, body-mass index (BMI), smoking history, lung cancer histology, chest CT, and other medical information were carefully collected for all subjects in the study. Pulmonary function-test data were exported from the MasterLab system (Jaeger, Höchberg, Germany). As a retrospective study, all data were anonymous. We declare that patients' data were confidential and did not compromise patient interests. After the approval of the ethics committee of Qilu Hospital of Shandong University (2015091), informed consent from participants was not required.

\section{Lung cancer diagnosis and histological classification}

Lung cancer was diagnosed based on preoperative and/or postoperative histopathology reports, and was categorized as adenocarcinoma, squamous-cell carcinoma (SCC), small-cell lung cancer (SCLC), large-cell carcinoma, large-cell neuroendocrine carcinoma (LCNC), adenosquamous carcinoma, carcinoid tumors, and other histological types. SCLC, LCNC, and carcinoid tumors were grouped together into neuroendocrine tumor types according to the WHO classification of lung cancer. ${ }^{28}$ The exclusion of lung cancer in the control group was done by an experienced radiologist and pulmonologist based on chest CT scan and clinical information. 


\section{Assessment of COPD and COPD severity}

All participants (lung cancer and controls) underwent PFTs performed by respiratory physicians. The Global Initiative for Chronic Obstructive Lung Disease (GOLD; 2005-2015) criteria were used to diagnose COPD and assign grades of severity: patients with postbronchodilator values of $\mathrm{FEV}_{1} /$ forced vital capacity $(\mathrm{FVC})<0.7$ were classified as COPD, $\mathrm{FEV}_{1} \geq 0.8$ as mild, $0.5 \leq \mathrm{FEV}_{1}<0.8$ moderate, $0.3 \leq$ $\mathrm{FEV}_{1}<0.5$ severe, and $\mathrm{FEV}_{1} \leq 0.3$ extremely severe. ${ }^{29}$

\section{Identification of COPD phenotypes}

AC on MEFV curve of diagnosed COPD patients was evaluated based on Topalovic's method of computer quantitative measurement. ${ }^{36}$ Raw PFT data points (sampling every $40 \mathrm{~mL}$ volume) of MEFV curves were exported from the MasterLab system and analyzed by the computer model. AC measurements were conducted under standard procedures using a computer model based on MatLab 8.5 (MathWorks, Natick, MA, USA). The procedure was performed according to previous work. ${ }^{37} \mathrm{~A}$ few COPD patients whose raw PFT data were not available were excluded from further analysis. Studies have demonstrated that sharp AC in the MEFV curve is an indicator of emphysema. ${ }^{35,36}$ According to our previous study, AC $137^{\circ}$ was chosen as an optimal cutoff point for categorizing COPD phenotypes: emphysema-predominant $\left(\mathrm{AC} \leq 137^{\circ}\right)$ and non-emphysema-predominant $\left(\mathrm{AC}>137^{\circ}\right)$.

\section{Statistical analysis}

Quantitative data are expressed as means \pm SD. Qualitative data are described using relative frequencies. Statistical differences between cases and controls and between-group differences were evaluated by $\chi^{2}$ tests or Student's $t$-test. Multivariable logistic regression was used to estimate ORs and $95 \%$ CIs for lung cancer and for each histological subtype associated with COPD or COPD phenotypes. Univariate analysis was performed on age, sex, BMI, smoking status, presence of COPD, grade of COPD clinical severity, and COPD phenotype as independent variables. These variables were subsequently introduced into a multivariate model to eliminate the possibility of mutual confounding. $P=0.05$ was considered statistically significant. All statistical analyses were performed using SPSS version 19.0.

\section{Results}

\section{Participant characteristics}

A total of 4,606 participants were collected from March 2004 to December 2015: 2,283 lung cancer cases and 2,323 non-lung cancer controls. The characteristics of participants are shown in Table 1. There was no significant difference in age, sex, or smoking status between lung cancer patients and controls ( $P=0.110,0.061$, and 0.745 , respectively). Significantly higher prevalence of COPD was observed in lung cancer patients $(32.8 \%$ [748]) compared to controls (16\% [371], $P<0.001)$. Furthermore, similar differences between lung cancer patients and controls were revealed in each grade of COPD. Histological subtypes found were adenocarcinoma (1,120 [49.1\%]), SCC (792 [34.7\%]), neuroendocrine carcinoma (192 [8.4\%], SCLC 152 [9.6\%], LCNC 20 [0.9\%], and carcinoid tumors $20[0.9 \%])$, large-cell carcinoma (58 [2.5\%]), adenosquamous carcinoma (46 [2.0\%]), and other histological types (14 [0.6\%]). More than $90 \%$ of lung cancers were at an early stage (stage IA-IIB).

Computed quantitative measurements of AC were performed on a total of $1,008(90.1 \%)$ COPD patients

Table I Characteristics of cases and controls

\begin{tabular}{|c|c|c|c|}
\hline & $\begin{array}{l}\text { Lung } \\
\text { cancer } \\
\text { cases } \\
(n=2,283)\end{array}$ & $\begin{array}{l}\text { Non-lung } \\
\text { cancer } \\
\text { controls } \\
(n=2,323)\end{array}$ & $P$-value \\
\hline Age, years (mean $\pm S D)$ & $60.3 \pm 9.5$ & $59.8 \pm 9.7$ & 0.110 \\
\hline Sex, n (\%) & & & 0.061 \\
\hline Male & I,719 (75.3) & $\mathrm{I}, 804(77.7)$ & \\
\hline Female & $564(24.7)$ & $519(22.3)$ & \\
\hline BMI, $\mathrm{kg} / \mathrm{m}^{2}($ mean $\pm \mathrm{SD})$ & $24.2 \pm 3.5$ & $23.4 \pm 3.4$ & $<0.001$ \\
\hline Smoking status, n (\%) & & & 0.745 \\
\hline Current and ex-smokers & $\mathrm{I}, 225$ & $\mathrm{I}, 258(54.2)$ & \\
\hline Nonsmokers & $\mathrm{I}, 058(46.3)$ & $\mathrm{I}, 065(45.8)$ & \\
\hline \multicolumn{4}{|l|}{ COPD, n (\%) } \\
\hline No & I,535 (67.2) & I,952 (84.0) & $<0.001$ \\
\hline Yes & $748(32.8)$ & $371(16.0)$ & $<0.001$ \\
\hline Mild & $554(24.3)$ & $305(13.1)$ & $<0.001$ \\
\hline Moderate & $163(7.1)$ & $62(2.7)$ & $<0.001$ \\
\hline Severe/extremely severe & $31(1.4)$ & $4(0.2)$ & $<0.001$ \\
\hline \multicolumn{4}{|l|}{ Histologic subtype, n (\%) } \\
\hline Adenocarcinoma & I, I $20(49.1)$ & NA & \\
\hline Squamous carcinoma & $792(34.7)$ & NA & \\
\hline Neuroendocrine carcinoma & $192(8.4)$ & NA & \\
\hline SCLC & $152(6.6)$ & NA & \\
\hline LCNC & $20(0.9)$ & NA & \\
\hline Carcinoid tumors & $20(0.9)$ & NA & \\
\hline Large-cell carcinoma & $58(2.5)$ & NA & \\
\hline Adenosquamous carcinoma & $46(2.0)$ & NA & \\
\hline Other subtypes@ & $14(0.6)$ & NA & \\
\hline Unclassified carcinoma & $61(2.7)$ & NA & \\
\hline \multicolumn{4}{|l|}{ Lung cancer stage, n (\%) } \\
\hline 1 & I,65I (72.3) & NA & \\
\hline II & $467(20.5)$ & NA & \\
\hline III-IV & $165(7.2)$ & NA & \\
\hline
\end{tabular}

Note: @Other subtypes include sarcomatoid carcinoma and pulmonary melanoma Abbreviations: BMI, body-mass index; SCLC, small-cell lung cancer; LCNC, largecell neuroendocrine carcinoma; NA, not applicable. 
(including lung cancer patients and controls). Briefly, 110 emphysema-predominant phenotypes (AC $129.2^{\circ} \pm 6.9^{\circ}$ ) and 898 non-emphysema-predominant phenotypes (AC $150.9^{\circ} \pm 7.1^{\circ}$ ) in COPD patients were identified. Patients with emphysema-predominant phenotypes had worse lung function $(P<0.001)$, were older $(P=0.024)$, and more of them were male $(P=0.028)$ compared to patients with the nonemphysema-predominant phenotype. Proportions of SCC and SCLC were also significantly higher among patients with the emphysema-predominant phenotype. Other characteristics of the two phenotypes are shown in Table 2.

\section{Associations between COPD and lung cancer risk}

Lung cancer risk factors are shown in Table 3. In univariate analysis, the presence of COPD was associated with an increased risk of lung cancer (OR 2.56, 95\% CI 2.23-2.95). Multivariable logistic regression analysis revealed that after age, sex, BMI, and smoking-status adjustment, the presence of COPD was an independent risk factor for lung cancer

Table 2 Characteristics of COPD phenotypes

\begin{tabular}{|c|c|c|c|}
\hline & $\begin{array}{l}\text { Emphysema- } \\
\text { predominant } \\
(\mathrm{n}=\mathrm{I} \mid 0)\end{array}$ & $\begin{array}{l}\text { Non- } \\
\text { emphysema- } \\
\text { predominant } \\
(\mathrm{n}=898)\end{array}$ & $P$-value \\
\hline Age, years (mean $\pm S D$ ) & $64.6 \pm 7.8$ & $62.6 \pm 8.4$ & 0.024 \\
\hline Sex, n (\%) & & & 0.028 \\
\hline Male & $104(94.5)$ & $785(87.4)$ & \\
\hline Female & $6(5.5)$ & $113(12.6)$ & \\
\hline $\mathrm{BMI}, \mathrm{kg} / \mathrm{m}^{2}($ mean $\pm \mathrm{SD})$ & $23.0 \pm 3.7$ & $23.3 \pm 3.4$ & 0.348 \\
\hline Smoking status, n (\%) & & & 0.445 \\
\hline Current and ex-smokers & $72(65.5)$ & $622(69.3)$ & \\
\hline Nonsmokers & $38(34.5)$ & $276(30.7)$ & \\
\hline $\mathrm{AC}($ mean $\pm \mathrm{SD})$ & $129.2 \pm 6.9$ & $150.9 \pm 7.1$ & $<0.001$ \\
\hline $\mathrm{FEV}_{1}, \mathrm{~L}($ mean $\pm \mathrm{SD})$ & $1.4 \pm 0.4$ & $2.1 \pm 0.6$ & $<0.001$ \\
\hline FVC, L (mean $\pm S D)$ & $2.9 \pm 0.7$ & $3.3 \pm 0.8$ & $<0.001$ \\
\hline $\mathrm{FEV}_{1} / \mathrm{FVC}, \%($ mean $\pm \mathrm{SD})$ & $50.0 \pm 9.6$ & $63.2 \pm 5.5$ & $<0.001$ \\
\hline Lung cancer subtype, n (\%) & $82(74.5)$ & $596(66.4)$ & \\
\hline Adenocarcinoma & $17(15.5)$ & $229(25.5)$ & 0.533 \\
\hline Squamous carcinoma & $41(37.3)$ & $270(30.1)$ & 0.033 \\
\hline Neuroendocrine carcinoma & $12(10.9)$ & $54(5.9)$ & 0.027 \\
\hline SCLC & $11(10.0)$ & $46(5.1)$ & 0.028 \\
\hline LCNC & I (0.9) & $4(0.4)$ & 0.366 \\
\hline Carcinoid tumors & NA & $4(0.4)$ & NA \\
\hline Large-cell carcinoma & $3(2.7)$ & $17(1.9)$ & 0.404 \\
\hline Adenosquamous carcinoma & I (0.9) & $7(0.8)$ & 0.516 \\
\hline Other subtypes@ & I (0.9) & $4(0.4)$ & 0.366 \\
\hline Unclassified carcinoma & $7(6.4)$ & $15(1.7)$ & 0.044 \\
\hline Non-lung cancer, n (\%) & $28(25.5)$ & $302(33.6)$ & 0.086 \\
\hline
\end{tabular}

Note: @Other subtypes include sarcomatoid carcinoma and pulmonary melanoma. Abbreviations: $\mathrm{AC}$, airway collapse; $\mathrm{BMI}$, body-mass index; $\mathrm{FEV}_{1}$, forced expiratory volume in I second; FVC, forced vital capacity; LCNC, large-cell neuroendocrine carcinoma; SCLC, small-cell lung cancer; NA, not applicable.
(OR 2.88, 95\% CI 2.48-3.34). After adjustment for age, sex, BMI, and smoking status, with increased COPD severity, the risk of lung cancer was significantly increased (OR 2.24, 95\% CI 1.99-2.51). In the same multivariable logistic regression model, female sex was also a risk factor for lung cancer.

\section{Relationships between COPD and risk of different lung cancer subtypes}

Lung cancer subtypes are presented in Table 4. After adjustment for age, sex, BMI, and smoking status, the presence of COPD indicated increased risk by two- to fivefold for each histological subtype of lung cancer compared with non-COPD. Among the most common subtypes, the odds for increased risk of SCLC were extremely high (OR 5.14, 95\% CI 3.58-7.39), followed by LCNC (OR 4.35, 95\% CI 1.68-11.3), SCC (OR 3.51, 95\% CI 2.90-4.23), large-cell carcinoma (OR 3.41, 95\% CI 1.94-5.98), and adenocarcinoma (OR 2.11, 95\% CI 1.74-2.55); Additionally, the presence of COPD increased the risk of neuroendocrine lung carcinoma by 4.28-fold (OR 4.28, 95\% CI 3.20-5.73). Moreover, after adjustment, with increased COPD severity, risks of the aforementioned subtypes were also significantly increased.

\section{Links between COPD phenotypes and risk of specific lung cancer histological subtypes}

In this study, COPD was categorized into two phenotypes: emphysema-predominant and non-emphysemapredominant. The presence of emphysema-predominant and non-emphysema-predominant COPD indicated increased risk of lung cancer by more than fourfold and twofold, respectively (OR 4.43, 95\% CI 2.85-6.88; OR 2.82, 95\% CI 2.40-3.31) (Table 3). Additionally, both phenotypes increased the risk of most subtypes of lung cancer, including adenocarcinoma, SCC, SCLC and large-cell carcinoma. Adjusted ORs for each subtype of lung cancer are shown in Table 4.

To clarify the difference of lung cancer risk between the two phenotypes, all non-COPD patients were removed from further analysis. Logistic regression analysis revealed that compared to patients with the non-emphysema-predominant phenotype, patients with emphysema-predominant COPD had significantly higher risk of lung cancer (adjusted OR 1.61, 95\% CI 1.02-2.54), especially SCC and SCLC (adjusted OR 1.72, 95\% CI 1.03-2.89; adjusted OR 3.74, $95 \%$ CI 1.64-8.53). For increased risks of other lung cancer subtypes, no significant difference was observed between the two phenotypes (Table 5). 
Table 3 Risk factors for lung cancer

\begin{tabular}{|c|c|c|c|c|c|c|}
\hline & \multicolumn{3}{|c|}{ Univariate analysis } & \multicolumn{3}{|c|}{ Logistic regression@ } \\
\hline & OR & $95 \% \mathrm{Cl}$ & $P$-value & OR & $95 \% \mathrm{Cl}$ & $P$-value \\
\hline COPD & 2.56 & $2.23-2.95$ & $<0.001$ & 2.88 & $2.48-3.34$ & $<0.001^{\mathrm{a}}$ \\
\hline COPD grading & 2.06 & $1.84-2.29$ & $<0.001$ & 2.24 & $1.99-2.5 \mid$ & $<0.00 I^{\mathrm{b}}$ \\
\hline Emphysema-predominant COPD & 3.72 & $2.4 I-5.75$ & $<0.001$ & 4.43 & $2.85-6.88$ & $<0.00 I^{c}$ \\
\hline Non-emphysema-predominant COPD & 2.51 & $2.15-2.93$ & $<0.001$ & 2.82 & $2.40-3.31$ & $<0.001^{\mathrm{d}}$ \\
\hline Age & 1.01 & $0.99-1.01$ & 0.110 & 1.00 & $0.99-1.00$ & $0.605^{\mathrm{a}}$ \\
\hline BMI & 1.07 & $1.05-1.09$ & $<0.001$ & 1.08 & $1.06-1.11$ & $<0.00 I^{a}$ \\
\hline Sex & 1.14 & $0.99-1.31$ & 0.059 & 1.32 & $1.12-1.56$ & $0.00 I^{a}$ \\
\hline Smoking status & 0.98 & $0.87-1.10$ & 0.735 & 1.00 & $0.87-1.15$ & $0.988^{\mathrm{a}}$ \\
\hline
\end{tabular}

Notes: @There were four multivariable logistic regression models: COPD (dichotomous, referent non-COPD), COPD grading (continuous, increase), emphysemapredominant COPD phenotype (dichotomous, referent non-COPD), and non-emphysema-predominant COPD phenotype (dichotomous, referent non-COPD) distributed in models I-4, respectively. Age (continuous, increase), BMI (continuous, increase), sex (dichotomous, referent male) and smoking status (dichotomous, referent nonsmoking) were common variables of models $\mathrm{I}-4,{ }^{\mathrm{a}}$ model I, ${ }^{\mathrm{b}}$ model $2,{ }^{\mathrm{c}}$ model $3,{ }^{\mathrm{d}}$ and model 4.

Abbreviation: BMI, body-mass index.

\section{Discussion}

The present study investigated the association between COPD phenotypes and specific histological lung cancer subtypes. Compared with previous studies, this study has a number of strengths, including large sample, participants collected without specific selection, confirmed diagnosis of lung cancer and COPD, and latest methods for categorizing subtypes or phenotypes. We found that after adjustment for age, sex, BMI, and smoking status, COPD was an independent risk factor for lung cancer and all common histological subtypes. Compared to non-COPD, both emphysema-predominant and non-emphysema-predominant phenotypes of COPD significantly increased the risk of lung cancer. Moreover, we demonstrated that there were some differences among different COPD phenotypes in relation to lung cancer risk: the increased risk of SCC and SCLC was significantly higher in patients with the emphysema-predominant phenotype compared to patients with the non-emphysema-predominant phenotype.

A number of studies have reported that approximately $40 \%-70 \%$ of lung cancers coexist with COPD. ${ }^{19,38,39}$ In the present study, high COPD prevalence was found in

Table 4 Risk factors for different histological subtypes of lung cancer@

\begin{tabular}{|c|c|c|c|c|c|}
\hline & $\begin{array}{l}\text { Squamous } \\
\text { carcinoma }^{\&}\end{array}$ & Adenocarcinoma $^{\&}$ & $\begin{array}{l}\text { Neuroendocrine } \\
\text { carcinoma }^{\&}\end{array}$ & SCLC ${ }^{\&}$ & LCNC $^{\&}$ \\
\hline $\mathrm{COPD}^{\mathrm{a}}$ & $3.51(2.90-4.23)^{\#}$ & $2.11(1.74-2.55)^{\#}$ & $4.28(3.20-5.73)^{\#}$ & $5.14(3.58-7.39)^{\#}$ & $4.35(1.68-11.3)^{\#}$ \\
\hline COPD grading ${ }^{\mathrm{b}}$ & $2.53(2.20-2.29)^{\#}$ & $1.72(1.49-2.00)^{\#}$ & $2.92(2.4 I-3.6 I)^{\#}$ & $3.32(2.6 \mathrm{I}-4.22)^{\#}$ & $3.69(2.04-6.68)^{\#}$ \\
\hline Emphysema-predominant phenotype ${ }^{c}$ & $5.96(3.44-9.4 I)^{\#}$ & $2.01(1.07-3.79)^{\#}$ & $8.73(4.47-17.1)^{\#}$ & $11.9(5.58-25.5)^{\#}$ & $9.80(1.10-82.3)^{\#}$ \\
\hline Non-emphysema-predominant phenotype ${ }^{d}$ & $3.40(2.78-4.17)^{\#}$ & $2.26(1.85-2.77)^{\#}$ & $3.68(2.76-5.08)^{\#}$ & $4.31(2.89-16.8)^{\#}$ & $2.80(0.85-9.18)^{*}$ \\
\hline $\mathrm{Age}^{\mathrm{a}}$ & $1.02(1.01-1.03)^{\#}$ & $0.99(0.99-1.00)^{*}$ & $0.97(0.96-0.98)^{\#}$ & $0.96(0.95-0.98)^{\#}$ & $0.99(0.93-1.01)^{*}$ \\
\hline $\mathrm{BMI}^{\mathrm{a}}$ & $1.08(1.05-1.10)^{\#}$ & $1.09(1.07-1.12)^{\#}$ & $1.07(1.03-1.11)^{\#}$ & $1.07(1.02-1.12)^{\#}$ & $0.99(0.87-1.12) *$ \\
\hline $\operatorname{Sex}^{\mathrm{a}}$ & $0.45(0.33-0.61)^{\#}$ & $1.78(1.48-2.16)^{\#}$ & $1.27(0.87-1.87)^{*}$ & $1.59(0.99-2.55)^{*}$ & $1.20(0.36-3.98) *$ \\
\hline \multirow[t]{2}{*}{ Smoking status ${ }^{\mathrm{a}}$} & $1.5 \mathrm{I}(1.23-1.85)^{\#}$ & $0.70(0.58-0.83)^{\#}$ & $1.16(0.84-1.61)^{*}$ & I.II $(0.73-1.68)^{*}$ & $0.77(0.27-2.19)^{*}$ \\
\hline & $\begin{array}{l}\text { Carcinoid } \\
\text { tumors }^{\&}\end{array}$ & $\begin{array}{l}\text { Large-cell } \\
\text { carcinoma }\end{array}$ & $\begin{array}{l}\text { Adenosquamous } \\
\text { carcinoma }^{\&}\end{array}$ & $\begin{array}{l}\text { Other } \\
\text { subtypes }^{\&}\end{array}$ & Unclassified $^{\&}$ \\
\hline $\mathrm{COPD}^{\mathrm{a}}$ & $1.75(0.74-6.16)^{*}$ & $3.41(1.94-5.98)^{\#}$ & $2.04(\mathrm{I} .0 \mathrm{I}-4.1 \mathrm{I})^{\#}$ & $5.26(1.84-18.1)^{\#}$ & $3.09(1.78-5.35)^{\#}$ \\
\hline COPD grading ${ }^{\mathrm{b}}$ & $1.47(0.63-3.45)^{*}$ & $2.27(1.53-2.71)^{\#}$ & $1.69(1.03-2.79)^{\#}$ & $2.44(1.17-5.09)^{\#}$ & $2.52(1.78-3.59)^{\#}$ \\
\hline Emphysema-predominant phenotype ${ }^{c}$ & NA & $5.56(1.55-19.9)^{\#}$ & $2.45(0.27-16.8)^{*}$ & $8.29(0.88-78.5)^{*}$ & $9.03(3.16-25.8)^{\#}$ \\
\hline Non-emphysema-predominant phenotype ${ }^{d}$ & $2.10(0.67-6.63)^{*}$ & $3.37(1.84-6.17)^{\#}$ & I.5I $(0.65-3.54)^{*}$ & $3.26(0.90-11.8)^{*}$ & $2.74(1.48-5.04)^{\#}$ \\
\hline $\mathrm{Age}^{\mathrm{a}}$ & $0.98(0.94-1.02)^{*}$ & $0.99(0.96-1.02)^{*}$ & $1.01(0.98-1.05)^{*}$ & $0.99(0.94-1.05)^{*}$ & $1.02(0.99-1.05)^{*}$ \\
\hline $\mathrm{BMl}^{\mathrm{a}}$ & $1.06(0.94-1.19)^{*}$ & $1.07(1.00-1.16)^{\#}$ & $1.12(1.03-1.21)^{\#}$ & $0.87(0.74-1.03)^{*}$ & $1.00(0.93-1.08)^{*}$ \\
\hline Sex ${ }^{a}$ & NA & $0.66(0.25-1.72)^{*}$ & $3.03(1.34-6.86)^{\#}$ & $2.17(0.4 \mathrm{I}-1 \mathrm{I} .5)^{*}$ & $1.20(0.56-2.55)^{*}$ \\
\hline Smoking status ${ }^{\mathrm{a}}$ & $0.86(0.31-2.45)^{*}$ & $1.73(0.89-3.35)^{*}$ & $1.97(0.90-4.33)^{*}$ & $2.35(0.52-10.6)^{*}$ & $1.30(0.70-2.43) *$ \\
\hline \multicolumn{6}{|c|}{$\begin{array}{l}\text { Notes: } @ \text { There were four multivariable logistic regression models, and each lung cancer subtype was analyzed respectively. COPD (dichotomous, referent non-COPD), } \\
\text { COPD grading (continuous, increase), emphysema-predominant COPD phenotype (dichotomous, referent non-COPD), and non-emphysema-predominant COPD phenotype } \\
\text { (dichotomous, referent non-COPD) distributed in models I-4, respectively. Age (continuous, increase), BMI (continuous, increase), sex (dichotomous, referent male) and } \\
\text { smoking status (dichotomous, referent non-smoking) were common variables of models I-4, }{ }^{2} \text { model I, }{ }^{b} \text { model 2, }{ }^{c} \text { model } 3,{ }^{d} \text { and model } 4 .{ }^{2} \text { Adjusted OR ( } 95 \% \text { Cl); }{ }^{\sharp P}<0.05 ; \\
* P>0.05 \text {. }\end{array}$} \\
\hline
\end{tabular}


Table 5 Risk of specific lung cancer subtypes in the presence of emphysema-predominant phenotype of COPD relative to nonemphysema-predominant phenotype

\begin{tabular}{llll}
\hline & \multicolumn{3}{l}{$\begin{array}{l}\text { Emphysema-predominant } \\
\text { phenotype of COPD }{ }^{\circledR}\end{array}$} \\
\cline { 2 - 4 } & OR & $\mathbf{9 5 \% ~ C l}$ & P-value \\
\hline All subtypes & $\mathrm{I} .6 \mathrm{I}$ & $\mathrm{I} .02-2.54$ & 0.043 \\
Adenocarcinoma & 0.89 & $0.46-1.7 \mathrm{I}$ & $0.72 \mathrm{I}$ \\
Squamous carcinoma & $\mathrm{I} .73$ & $1.03-2.89$ & 0.038 \\
Neuroendocrine carcinoma & 3.09 & $1.50-6.35$ & 0.002 \\
$\quad$ SCLC & 3.74 & $1.64-8.53$ & 0.002 \\
LCNC & 2.94 & $0.31-28.1$ & 0.349 \\
Carcinoid tumors & $\mathrm{NA}$ & $\mathrm{NA}$ & $\mathrm{NA}$ \\
Large-cell carcinoma & 2.24 & $0.60-8.37$ & 0.230 \\
Adenosquamous carcinoma & 1.89 & $0.21-16.7$ & 0.567 \\
Other subtypes & 3.28 & $0.29-37.6$ & 0.340 \\
Unclassified carcinoma & 2.54 & $0.85-7.6 \mathrm{I}$ & 0.096 \\
\hline Notes:
\end{tabular}

Notes: @Each lung cancer subtype was analyzed separately. Multivariable logistic regression model variables: emphysema-predominant phenotype of COPD (dichotomous, referent non-emphysema-predominant phenotype), age (continuous, increase), BMI (continuous, increase), sex (dichotomous, referent male), and smoking status (dichotomous, referent nonsmoking).

Abbreviations: BMI, body-mass index; SCLC, small cell-lung cancer; LCNC, largecell neuroendocrine carcinoma; NA, not applicable.

2,283 patients with lung cancer (32.8\%). Even though our data appear to reveal the lowest percentages published thus far, ${ }^{19-21,38,39}$ they also appear to be very accurate. Briefly, in a previous study COPD was diagnosed using different criteria, including self-report evaluation, ${ }^{20}$ which might have led to overdiagnosis. Moreover, certain studies were performed only on smokers. ${ }^{19,21,40}$ Our lung cancer cases were not specifically selected (such as targeting population at higher risk). During subgroup analysis, we found that the prevalence of COPD in lung cancer cases was $42.4 \%$ in smokers compared to $21.8 \%$ in nonsmokers (data not shown). This was consistent with previous results. In order to avoid the potential impact of resection on lung function, ${ }^{41}$ PFTs were performed after lung cancer diagnosis but before surgery. Young et al reported that there were no significant changes in lung function before and after lung cancer diagnosis. ${ }^{19}$ As such, the results from this study should be more comparable to the prevalence of COPD in the overall lung cancer population. Besides, the prevalence of COPD in matched hospital-based controls was $16 \%$, somewhat higher but still in line with recently published studies on COPD prevalence. ${ }^{6}$

Previous prospective studies have provided evidence for increased risk of lung cancer in the presence of COPD. Wasswa-Kintu et al demonstrated that there was an inverse relationship between lung function and lung cancer incidence in smokers. ${ }^{17}$ Furthermore, a cohort of 2,507 COPD outpatients without lung cancer was followed for a 5-year period, during which time 215 patients had developed cancer (incidence density of 16.7 per 1,000 person-years).$^{18}$ Moreover, Turner et al strengthened the evidence of increased risk of COPD for lung cancer in nonsmokers. ${ }^{42}$ In the present study, we found that the presence of COPD increased the risk of lung cancer by 2.88 -fold, after adjusting for age, sex, BMI, and smoking status. COPD has been reported to increase the risk of lung cancer by two to sixfold in some small case-control studies. ${ }^{19,38}$ de Torres et al observed an inverse relationship between the incidence of lung cancer and the severity of COPD. ${ }^{18}$ On the contrary, we observed that the risk of lung cancer was significantly increased following increased GOLD grade. A potential explanation is that patients with more severe COPD died at an early point during the study, revealing a decrease in the number of severe COPD patients at risk as the prospective study progressed. Nevertheless, the "survival bias" can be effectively avoided in case-control study. Besides, in this study, the same relationships were also observed in nonsmokers and female subgroups, and were consistent with the results reported by two specific population studies. ${ }^{40,42}$ The results were not in line with another study conducted in southern China in that they reported no significant relationship between previous COPD (including COPD, emphysema and chronic bronchitis) and the risk of lung cancer in nonsmokers. ${ }^{43}$ This requires a larger multicenter study to verify.

Although the aforementioned studies have confirmed that the presence of COPD increases the risk of lung cancer, they were neither designed nor powered to detect differential links between COPD and risks of histological subtypes. The most important limitation in reported studies was the small number of recorded lung cancer, insufficient to provide enough histological subtypes. A prospective study has just found SCC was the most frequent histological subtype. ${ }^{18}$ In other studies, obtaining the histological types of lung cancer was very challenging. ${ }^{19,42,43}$ Herein, lung cancer was proven by biopsy or operative histology, avoiding possible bias resulting from inaccurate diagnosis. The cases included in the study were collected over more than a decade, and they included all common lung cancer subtypes. Some subtypes are very recent, and have rarely been mentioned in similar studies, such as LCNC and neuroendocrine carcinoma, which was an important update in the latest WHO classification of lung tumors. ${ }^{28}$ Consequently, the proportion of each subtype was very close to the epidemiological distribution of lung cancer subtypes. ${ }^{44}$ We revealed that the presence of COPD indicated an increased risk of two- to five-fold for all histological subtypes, except for carcinoid tumors. The risk odds for SCLC were highest, followed by LCNC, SCC, 
large cell-carcinoma, and adenocarcinoma. Furthermore, the association between the risk of neuroendocrine carcinoma and COPD was studied for the first time, and the presence of COPD was found to increase the risk of neuroendocrine lung carcinoma by 4.28 -fold.

Only one previous study, conducted in Taiwan, has mentioned that male and female patients with COPD had increased risks for SCC, adenocarcinoma, and SCLC. Contrary to our results, the HRs of the three subtypes were lower and very similar. ${ }^{45}$ Moreover, Papi et al reported that among smokers with NSCLC, COPD was a risk factor for SCC, ${ }^{21}$ which was also observed in our study. Besides, our results showed that female sex was also a risk factor for lung cancer. This would be mostly due to the high prevalence of adenocarcinoma in this study. Subgroup analysis showed that female sex was an independent risk factor for adenocarcinoma, not other histological subtypes. We believe ours is the first well-designed case-control study to provide ORs for risk of all histological subtypes of lung cancer according to the presence or absence of COPD.

As is well known, COPD is a very heterogeneous disease, and so the question arises: Is there any link between COPD phenotypes and the risk related to specific histological subtype of lung cancer? Previous studies have suggested that lung cancer is associated with a history of emphysema and chronic bronchitis, ${ }^{46-51}$ and emphysema and chronic bronchitis are considered traditional clinical phenotypes of COPD. ${ }^{32}$ In most studies, the diagnosis of emphysema and chronic bronchitis relied on self-report and was subject to recall bias and misclassification. In order to reduce the potential for disease misclassification, researchers have attempted to evaluate the association between computed CT evidence of emphysema and/or airflow obstruction and the risk of lung cancer. They indicated that the presence of CT evidence of emphysema could increase the risk of lung cancer by two to fourfold, but there was no or lower risk of lung cancer associated with airflow obstruction. ${ }^{46-49}$ Recently, two studies have attempted to explore the impact of COPD phenotypes categorized by QCT on lung cancer risk. ${ }^{51,52}$ Their results were inconsistent with previous studies reporting that QCT measurements of emphysema and airway dimensions were not significantly associated with lung cancer risk. This implies that methods used to determine COPD phenotypes might be very important.

In the present study, computer quantification of $\mathrm{AC}$ on the MEFV curve was used to categorize phenotypes: emphysema-predominant and non-emphysema-predominant. ${ }^{35-37}$ The results obtained showed that compared to non-COPD, both phenotypes independently increased the risk of overall lung cancer and most lung cancer subtypes (including adenocarcinoma, SCC, SCLC, and large-cell carcinoma). A previous cross-sectional study reported that the risk odds of SCC were significantly increased among lung cancer patients with emphysema. ${ }^{53}$ Further analysis in our study found that patients with the emphysema-predominant phenotype of COPD had higher risk of SCC and small-cell carcinoma compared with patients with the non-emphysema-predominant phenotype of COPD. Increased risk for other subtypes of lung cancer was not significantly different between the two phenotypes. To the best of our knowledge, this study is the first to successfully compare differences between the impacts of COPD phenotypes on risks related to specific histological subtypes of lung cancer.

With this study, we have presented a comprehensive evaluation of the relationship between COPD phenotypes and histological subtypes of lung cancer. Though our results would not clarify directly the specific mechanistic link between COPD and lung cancer, they can certainly provide important implications and guidance for research into the mechanism between the two diseases. On one hand, we found differences among links between COPD phenotypes and specific lung cancer histological subtypes. The strong association between SCC and emphysema-predominant phenotype of COPD can be partly explained by smokinginduced upregulated matrix metalloproteinase and excessive inflammatory and oxidative stress responses. ${ }^{19,21,54}$ SCLC is also strongly related to smoking and emphysema. ${ }^{13,49}$ As such, whether there is shared genetic susceptibility to chronic smoking-induced inflammation between SCLC and emphysema or other common mechanisms still requires more concrete research. On the other hand, COPD and its phenotypes can significantly increase the risk of almost all lung cancer subtypes. Therefore, we believe there must be some common mechanism between the pathogenesis of lung cancer and COPD that is not affected by disease heterogeneity. This hypothesis requires further studies and confirmation.

\section{Limitations}

We recognize that there were several limitations in this study. Firstly, computed quantitative measurement of AC is a reliable method to identify the emphysema-predominant phenotype of COPD, but non-emphysema-predominant phenotype may include airway-dominant and mixed phenotypes. A more precise link between the airway-dominant phenotype of COPD and lung cancer still needs further study. Secondly, PFTs of all lung cancers in this study were performed after 
lung cancer diagnosis. We were not able to assess the effect of lung cancer itself on lung function and the MEFV curve form, although most lung cancers in this study were at an early stage and previous research has shown no significant changes in lung function before and after lung cancer diagnosis. ${ }^{19} \mathrm{SCC}$ and SCLC tend toward more central localization. Though Papi et al indicated that central lung cancer did not represent an increased risk of airflow limitation, ${ }^{21}$ it remains to be seen whether central lung cancer can affect the occurrence and development of emphysema. Thirdly, inhaled corticosteroids (ICSs) are commonly prescribed to COPD patients. We did not get the relevant information regarding the use of ICSs. However, several studies have demonstrated that regular ICS use in COPD patients was significantly associated with decreased lung cancer risk, especially the use of higher ICS doses $\left(\geq 1,200 \mu \mathrm{g} /\right.$ day). ${ }^{55-57}$ Their potential role in cancer prevention should not be ignored. In addition, according to the latest classification of lung tumors, many lung SCCs of the past are now classified as adenocarcinoma. ${ }^{28}$ This study could not assess the impact of this update on the relationship between COPD and lung cancer risk. Lastly, we could not provide the lung cancer-incidence rate in the presence of COPD in this case-control study, and this remains uncertain in Chinese populations. Further well-designed prospective studies are necessary to solve these problems.

\section{Conclusion}

This study provides more evidence on the links between COPD and lung cancer. COPD is an independent risk factor for lung cancer and all common histologic subtypes. Both emphysema-predominant and non-emphysema-predominant phenotypes of COPD significantly increased the risk of lung cancer. Compared to the non-emphysema-predominant phenotype of COPD, the emphysema-predominant phenotype had a higher risk of SCC and SCLC, but not other histologic subtypes.

\section{Acknowledgments}

This work was supported by the National Natural Science Foundation of China (81370148) and the Shandong Natural Science Project (ZR2012HQ011).

\section{Disclosure}

The authors report no conflicts of interest in this work.

\section{References}

1. Torre LA, Bray F, Siegel RL, Ferlay J, Lortet-Tieulent J, Jemal A. Global cancer statistics, 2012. CA Cancer J Clin. 2015;65(2):87-108.
2. Siegel RL, Miller KD, Jemal A. Cancer statistics, 2016. CA Cancer J Clin. 2016;66(1):7-30.

3. Chen WQ, Zheng RS, Baade PD, et al. Cancer statistics in China, 2015. CA Cancer J Clin. 2016;66(2):115-132.

4. Chen WQ, Zheng RS, Zeng HM, Zhang SW. Epidemiology of lung cancer in China. Thorac Cancer. 2015;6(2):209-215.

5. Adeloye $\mathrm{D}, \mathrm{Chua} \mathrm{S}, \mathrm{Lee} \mathrm{C}$, et al. Global and regional estimates of COPD prevalence: systematic review and meta-analysis. J Glob Health. 2015; 5(2):020415.

6. Yin $\mathrm{P}$, Wang $\mathrm{H}$, Vos $\mathrm{T}$, et al. A subnational analysis of mortality and prevalence of COPD in China from 1990 to 2013: findings from the Global Burden of Disease study 2013. Chest. 2016;150(6):1269-1280.

7. Lozano R, Naghavi M, Foreman K, et al. Global and regional mortality from 235 causes of death for 20 age groups in 1990 and 2010 : a systematic analysis for the Global Burden of Disease study 2010. Lancet. 2012;380(9859):2095-2128.

8. Halbert RJ, Natoli JL, Gano A, Badamgarav E, Buist AS, Mannino DM. Global burden of COPD: systematic review and meta-analysis. Eur Respir J. 2006;28(3):523-532.

9. GBD 2013 Mortality and Causes of Death Collaborators. Global, regional, and national age-sex specific all-cause and cause-specific mortality for 240 causes of death, 1990-2013: a systematic analysis for the Global Burden of Disease study 2013. Lancet. 2015;385(9963): $117-171$.

10. Dai J, Yang P, Cox A, Jiang G. Lung cancer and chronic obstructive pulmonary disease: from a clinical perspective. Oncotarget. 2017;8(11): 18513-18524.

11. Loomis D, Grosse Y, Lauby-Secretan B, et al. The carcinogenicity of outdoor air pollution. The Lancet Oncol. 2013;14(13):1262-1263.

12. Moolgavkar SH, Holford TR, Levy DT, et al. Impact of reduced tobacco smoking on lung cancer mortality in the United States during 1975-2000. J Natl Cancer Inst. 2012;104(7):541-548.

13. Pesch B, Kendzia B, Gustavsson P, et al. Cigarette smoking and lung cancer: relative risk estimates for the major histological types from a pooled analysis of case-control studies. Int J Cancer. 2012;131(5): 1210-1219.

14. Eisner M, Anthonisen N, Coultas D, et al. An official American Thoracic Society public policy statement: novel risk factors and the global burden of chronic obstructive pulmonary disease. Am J Respir Crit Care Med. 2015;182(5):693-718.

15. Powell HA, Iyen-Omofoman B, Baldwin DR, Hubbard RB, Tata LJ. Chronic obstructive pulmonary disease and risk of lung cancer: the importance of smoking and timing of diagnosis. J Thorac Oncol. 2013; 8(4):e34-e35.

16. Tockman MS, Anthoniden NR, Wright EC, Donithan MG. Airways obstruction and the risk for lung cancer. Ann Intern Med. 1987;106(11): $512-518$.

17. Wasswa-Kintu S, Gan WQ, Man SF, Pare PD, Sin DD. Relationship between reduced forced expiratory volume in one second and the risk of lung cancer: a systematic review and meta-analysis. Thorax. 2005; 60(7):570-575.

18. de Torres JP, Marin JM, Casanova C, et al. Lung cancer in patients with chronic obstructive pulmonary disease: incidence and predicting factors. Am J Respir Crit Care Med. 2011;184(8):913-919.

19. Young RP, Hopkins RJ, Christmas T, Black PN, Metcalf P, Gamble GD. COPD prevalence is increased in lung cancer, independent of age, sex and smoking history. Eur Respir J. 2009;34(2):380-386.

20. Schwartz AG, Cote ML, Wenzlaff AS, et al. Chronic obstructive lung diseases and risk of non-small cell lung cancer in women. $J$ Thorac Oncol. 2009;4(3):291-299.

21. Papi A, Casoni G, Caramori G, et al. COPD increases the risk of squamous histological subtype in smokers who develop non-small cell lung carcinoma. Thorax. 2004;59(8):679-681.

22. Prevot G, Plat G, Mazieres J. [COPD and lung cancer: epidemiological and biological links]. Rev Mal Respir. 2012;29(4):545-556. French.

23. Durham AL, Adcock IM. The relationship between COPD and lung cancer. Lung Cancer. 2015;90(2):121-127. 
24. Houghton AM. Mechanistic links between COPD and lung cancer. Nat Rev Cancer. 2013;13(4):233-245.

25. Young RP, Hopkins RJ, Whittington CF, Hay BA, Epton MJ, Gamble GD. Individual and cumulative effects of GWAS susceptibility loci in lung cancer: associations after sub-phenotyping for COPD. PLoS One. 2011;6(2):e16476.

26. de-Torres JP, Sanchez-Salcedo P, Bastarrika G, et al. Telomere length, COPD and emphysema as risk factors for lung cancer. Eur Respir $J$. 2017;49(1):1601521.

27. Tessema M, Yingling CM, Picchi MA, et al. Epigenetic repression of CCDC37 and MAP1B links chronic obstructive pulmonary disease to lung cancer. J Thorac Oncol. 2015;10(8):1181-1188.

28. Travis WD, Brambilla E, Nicholson AG, et al. The 2015 World Health Organization classification of lung tumors: impact of genetic, clinical and radiologic advances since the 2004 classification. J Thorac Oncol. 2015;10(9):1243-1260.

29. Vogelmeier CF, Criner GJ, Martinez FJ, et al. Global strategy for the diagnosis, management, and prevention of chronic obstructive lung disease 2017 report: GOLD executive summary. Respirology. 2017; 22(3):575-601.

30. MacNee W. Computed tomography-derived pathological phenotypes in COPD. Eur Respir J. 2016;48(1):10-13.

31. Schwartz AG, Cote ML. Epidemiology of lung cancer. Adv Exp Med Biol. 2016;893:21-41.

32. Friedlander AL, Lynch D, Dyar LA, Bowler RP. Phenotypes of chronic obstructive pulmonary disease. COPD. 2007;4(4):355-384.

33. Han MK, Agusti A, Calverley PM, et al. Chronic obstructive pulmonary disease phenotypes: the future of COPD. Am J Respir Crit Care Med. 2010;182(5):598-604.

34. Subramanian DR, Gupta S, Burggraf D, et al. Emphysema- and airwaydominant COPD phenotypes defined by standardised quantitative computed tomography. Eur Respir J. 2016;48(1):92-103.

35. Healy F, Wilson AF, Fairshter RD. Physiologic correlates of airway collapse in chronic airflow obstruction. Chest. 1984;85(4):476-481.

36. Topalovic M, Exadaktylos V, Peeters A, et al. Computer quantification of airway collapse on forced expiration to predict the presence of emphysema. Respir Res. 2013;14:131.

37. Wang W, Xie M, Dou S, Cui L, Xiao W. Computer quantification of "angle of collapse" on maximum expiratory flow volume curve for diagnosing asthma-COPD overlap syndrome. Int $J$ Chron Obstruct Pulmon Dis. 2016;11:3015-3022.

38. Loganathan RS, Stover DE, Shi W, Venkatraman E. Prevalence of COPD in women compared to men around the time of diagnosis of primary lung cancer. Chest. 2006;129(5):1305-1312.

39. Ytterstad E, Moe PC, Hjalmarsen A. COPD in primary lung cancer patients: prevalence and mortality. Int $J$ Chron Obstruct Pulmon Dis. 2016;11:625-636.

40. Schwartz AG, Lusk CM, Wenzlaff AS, et al. Risk of lung cancer associated with COPD phenotype based on quantitative image analysis. Cancer Epidemiol Biomarkers Prev. 2016;25(25):1341-1347.

41. Win T, Jackson A, Sharples L, et al. Relationship between pulmonary function and lung cancer surgical outcome. Eur Respir J. 2005; 25(4):594-599.
42. Turner MC, Chen Y, Krewski D, Calle EE, Thun MJ. Chronic obstructive pulmonary disease is associated with lung cancer mortality in a prospective study of never smokers. Am J Respir Crit Care Med. 2007; 176(3):285-290.

43. Wang H, Yang L, Zou L, et al. Association between chronic obstructive pulmonary disease and lung cancer: a case-control study in southern Chinese and a meta-analysis. PLoS One. 2012;7(10):e46114.

44. Gabrielson E. Worldwide trends in lung cancer pathology. Respirology. 2006;11(5):533-538.

45. Huang JY, Jian ZH, Nfor ON, et al. The effects of pulmonary diseases on histologic types of lung cancer in both sexes: a population-based study in Taiwan. BMC Cancer. 2015;15:834.

46. de Torres JP, Bastarrika G, Wisnivesky JP, et al. Assessing the relationship between lung cancer risk and emphysema detected on low-dose CT of the chest. Chest. 2007;132(6):1932-1938.

47. Wilson DO, Weissfeld JL, Balkan A, et al. Association of radiographic emphysema and airflow obstruction with lung cancer. Am J Respir Crit Care Med. 2008;178(7):738-744.

48. Maldonado F, Bartholmai BJ, Swensen SJ, Midthun DE, Decker PA, Jett JR. Are airflow obstruction and radiographic evidence of emphysema risk factors for lung cancer? A nested case-control study using quantitative emphysema analysis. Chest. 2010;138(6):1295-1302.

49. Li Y, Swensen SJ, Karabekmez LG, et al. Effect of emphysema on lung cancer risk in smokers: a computed tomography-based assessment. Cancer Prev Res (Phila). 2011;4(1):43-50.

50. Brenner DR, McLaughlin JR, Hung RJ. Previous lung diseases and lung cancer risk: a systematic review and meta-analysis. PLoS One. 2011; 6(3):e17479.

51. Smith BM, Pinto L, Ezer N, Sverzellati N, Muro S, Schwartzman K. Emphysema detected on computed tomography and risk of lung cancer: a systematic review and meta-analysis. Lung Cancer. 2012; 77(1):58-63.

52. Gierada DS, Guniganti P, Newman BJ, et al. Quantitative CT assessment of emphysema and airways in relation to lung cancer risk. Radiology. 2011;261(3):950-959.

53. Smith BM, Schwartzman K, Schwartzman K, et al. Lung cancer histologies associated with emphysema on computed tomography. Lung Cancer. 2012;76(1):61-66.

54. Bozinovski S, Vlahos R, Anthony D, et al. COPD and squamous cell lung cancer: aberrant inflammation and immunity is the common link. Br J Pharmacol. 2016;173(4):635-648.

55. Kiri VA, Fabbri LM, Davis KJ, Soriano JB. Inhaled corticosteroids and risk of lung cancer among COPD patients who quit smoking. Respir Med. 2009;103(1):85-90.

56. Parimon T, Chien JW, Bryson CL, McDonell MB, Udris EM, Au DH. Inhaled corticosteroids and risk of lung cancer among patients with chronic obstructive pulmonary disease. Am J Respir Crit Care Med. 2007;175(7):712-719.

57. Raymakers AJ, McCormick N, Marra CA, Fitzgerald JM, Sin D, Lynd LD. Do inhaled corticosteroids protect against lung cancer in patients with COPD? A systematic review. Respirology. 2017; 22(1):61-70
International Journal of COPD

\section{Publish your work in this journal}

The International Journal of COPD is an international, peer-reviewed journal of therapeutics and pharmacology focusing on concise rapid reporting of clinical studies and reviews in COPD. Special focus is given to the pathophysiological processes underlying the disease, intervention programs, patient focused education, and self management protocols.

\section{Dovepress}

This journal is indexed on PubMed Central, MedLine and CAS. The manuscript management system is completely online and includes a very quick and fair peer-review system, which is all easy to use. Visit http://www.dovepress.com/testimonials.php to read real quotes from published authors. 